\title{
Comparative allelopathic effects of mango, litchi, sal forest leaf litter on the germination and seedling growth of rice (Oryza sativa) Menovikho Hoshi, Kamla Dhyani*, Shweta Sahni, Chhaya Singh
}

Doon (P.G) College of Agriculture Science and Technology

Shri Guru Ram Rai Institute of Technology \& Sciences, Dehradun Uttrakhand, India.

Received: July 12, 2016; Accepted: July 25, 2016.

\begin{abstract}
The present investigation is carried out to study the effect of leaf litter extract on the other crop. Allelopathic is the, phytotoxic effect of plants leaf on the other plants is well known. Some plants whether orchard crop or forest trees releases some chemicals which effects negatively sometimes positively to the growth of the other plants. In the present study it was studied that how the soil treated with leaf litter powder of trees (Litchi, Mango, Forest tree) is effected the growth and development of other plant. In an orchard generally leaf litter is the important source of allelochemicals in the soil. Litchi, Mango and forest litter all inhibit the growth of the test crop(Rice) but maximum inhibition is recorded by Litchi leaf powder treatment followed by mango and Forest whether Agriculture soil is treated as control in this case. Germination \%, MDA content, Root shoot dry weight is highly affected but chlorophyll was maximum recorded from litchi leaf treatment.
\end{abstract}

Key words: Allelopathic; phytotoxic; MDA content; leaf litter

\section{Introduction}

Allelopathy is a phenomenon mediated by chemicals secreted by the plants part and can be define as any positive or negative effect one plant can have on neighbouring species. This term was first coined by Hans Molisch deriving from Greek word "allelo-mutual, pathy-suffering". Soil is a very complex physical, chemical, and biological system. It is a part of Earth's crust in which plants are anchored and nutrient released from dead organic matters by variety of organisms for utilization of plants. In the soil environment there are many different chemicals called allelochemicals released from plants. In agricultural systems allelopathy can be part of the interference between crops and between crops and weeds and thus affecting the economical value of the plant production. Allelopathy is an important mechanism of plant interference and is mediated through the addition of chemicals to the plant environment. Besides, living plants exuding the allelochemicals, microbial decay of plants residue also release the toxic metabolites into the soil. Allelochemicals are present in the roots, rhizomes, stems, leaves, flowers, pollens, fruits and seeds but the leaves are the major source. The concentration of allelochemicals varies with age, season, plant parts and growth habit etc. The phytotoxic ability of these chemicals depends on type of plant, activity of microflora, their release and removal from the soil solution or immobilized by the plant uptake, adsorption to the soil particles and degradation by micro-organism. During allelopathic interaction, not only biochemicals substances secreted by plants may be involved but also some other inorganic elements like heavy metals and salts in soil can occur by hyper accumulation and litter decomposition and by change in rhizosphere chemistry. The different plant species which are known for their allelopathic potential such as Prosopis juliflora, Lantana camara, Tamarindus indicus, Datura so on. These are reported to curb the growth of the plant by releasing allelochemicals. Some of the allelochemicals inhibits the germination process and cause the failure of germination, while some hinders with the growth of radical and plumule. The physicochemical properties of soil are reported to influence some of the chemicals when released into the soil.

\section{Materials and Methods \\ Study sites}

The experiment was conducted at Doon (P.G) College of Agriculture Science and Technology, Selaqui, Dehradun during the month of April 2014. The test crop taken was Oryza sativa, grown in four different soils. The methodology of this project involves pot experiment. For this, the soils were collected from four different sites at different depth and the seeds were grown in the pots containing composite soil.

\section{Extract preparation}

Pot experiments were carried out under natural conditions at the Doon (p.g) college, during two successive summer seasons in August of 2013 and 2014. The use of mango, litchi, forest litter were shade dried. The dried leaves were ground to a fine powder. $5 \mathrm{~g}$ were transferred to labelled bottles, and then $100 \mathrm{ml}$ of sterile, deionized distilled water were added to each bottle. The mixture was

\section{${ }^{*}$ Corresponding Author:}

Dr. Chhaya Singh,

Department of Life Sciences,

Shri Guru Ram Rai Institute of Science,

Dehradun, Uttarakhand, India.

E-mail: singh_june07@,rediffmail.com 
shaken and the bottles were left for $48 \mathrm{~h}$ at room temperature, and then filtered to get extracts of these quantities were reduplicated. Seeds of rice were planted in plastic pots filled with $1 \mathrm{~kg}$ of soil. After 2 days from planting, extracts at $10 \%$ concentration were added to each pot at a rate of $500 \mathrm{ml} /$ pot weekly for one month. To check the allelochemicals released by litter and there effects on the seed germination and seedling growth. And other parameters are measured by following methods.

\section{Moisture Content \& Soil PH}

Fresh weight and the dry weight of soil is determined to estimate the moisture content using following formula,

Moisture content $\%=\frac{\text { Fresh weight of soil }- \text { dry weight of soil }}{\text { Fresh weight of soil }} \times 100$

The $\mathrm{pH}$ of the soils were analyze in a digital $\mathrm{pH}$ meter. $5 \mathrm{~g}$ of dried soil sample measured in $\mathrm{t}$

\section{Chlorophyll estimation}

Chlorophyll content in the leave sample was done according to Hiscox and Israelstam (1979) method. After the incubation the $.5 \mathrm{gm}$ leaves in $10 \mathrm{ml} \mathrm{DMSO}$, the absorbance was determine in spectrophotometer at wavelength of $663 \mathrm{~nm}$ and $645 \mathrm{~nm}$ against pure DMSO as blank.

Total chlorophyll contain was determine using following formula

$$
\begin{gathered}
\text { Total chlorophyll }(\mathrm{mg} / \mathrm{g})=[20.2(\mathrm{~A} 645)+8.02 \\
(\mathrm{A663)}) \times \mathrm{V} / 1000 \times \mathrm{W}
\end{gathered}
$$

Where, $A=$ absorbance of spectrophotometer

$\mathrm{V}=$ volume of blank

$\mathrm{W}=$ weight of leave

\section{Melondialdehyde (MDA) Assay}

The extend of lipid peroxidation in the leaves was estimated by measuring the amount of MDA by the method describe by Heath and Packer (1968), which takes into account the possible influence of the interfering compounds in the assay for Thiobarbytric acid (TBA) reactive substances.

MDA level (microgram mol) $=\operatorname{delta}($ A $532 \mathrm{~nm}-\mathrm{A}$ $600 \mathrm{~nm}) / 1.56$

\section{Collection and sterilisation of seeds}

Healthy and viable seeds of rice (Oryza sativa) were obtained from G.B Pant University of Uttarakhand. The seeds were sterilized with $1 \%$ Sodium hypochloride before the germination is done for about 20 minutes. These sterilized seeds were washed several times with distilled water to remove excess of chemicals.

\section{Germination percentage}

The viable seeds after sterilization were sown and were determine for its germination percentage in the $30^{\text {th }}$ day after sown. All the pots were determine for its germination using the formula,
Germination $\%=\frac{\text { Total number of germinated seeds }}{\text { Total number of seed sown }} \times 10^{0}$

Pot experiment was conducted for the soil treated with $5 \%$ extract of each litter (Mango, Litchi, Forest litter) and soil of a agricultural field as control, to determine and compare the variation in germination pattern. The study of rice germination reveals variation in its growth with different treatments soil. The results obtained from the experiment are given under the following heads:

\section{Results and Discussion}

Pot experiment was conducted for the soil treated with $5 \%$ extract of each litter (Mango, Litchi, Forest litter) and soil of a agricultural field as control, to determine and compare the variation in germination pattern. The study of rice germination reveals variation in its growth with different treatments soil. The results obtained from the experiment are given under the following heads. Rice seeds germination in forest soil shows different germinating pattern with an average germination percentage of $83 \%$. The root length and shoot length of seeds growing in this soil increases with continuing growing day. The mean shoot height was found to be $19.63 \mathrm{~cm}$ and mean root length was 3.49. The total chlorophyll contains and the MDA level as determined by spectrophotometer in seedling is 575.94 and 1.82 respectively. The biomass (fresh weight- dry weight) present in the germinating seedling is $0.117 \mathrm{~g}$.

The mean seed germination percentage in this soil is $78.75 \%$. The shoot and root development is better in this soil comparing to forest soil in term of height and length. The mean height of shoot and root length were found to be $21.54 \mathrm{~cm}$ and $3.91 \mathrm{~cm}$. The chlorophyll contains and the total MDA level was varies from 448.40 and 2.41 respectively. Biomass concentration was found to be $0.093 \mathrm{~g}$. Seeds developing shoot and root in these soils shows better result comparing to seeds in other soils.

Seeds grown in Litchi soil indicate the lowest in terms of germination, shoot and root development as compared to seeds grown in other soils. In this soil the germination percentage was found to be lowest having $66.25 \%$. The shoot and root development also lower greatly in comparison to other seed. The average height of shoot and root length were found to be $15.56 \mathrm{~cm}$ and $2.70 \mathrm{~cm}$. But contradictory to growth, root and shoot development the chlorophyll content is higher having 614.62. The MDA level and the biomass content were found to be 3.88 and $0057 \mathrm{~g}$. 


\section{Germination pattern in agriculture soil}

The highest germination percentage was shown by agriculture soil with an average growth of $91.5 \%$, although their root and shoot development varies dramatically. Highest average shoot length was found to be $21.77 \mathrm{~cm}$ and root length was $3.83 \mathrm{~cm}$. The chlorophyll and MDA level varies from 542.33 and 1.37. The biomass contain was found to be $0.068 \mathrm{~g}$.

Table 1: Showing Average shoot and root length, chlorophyll content, MDA level and biomass present in the seedling under different soil treatment.

\begin{tabular}{|c|c|c|c|c|c|c|}
\hline $\begin{array}{c}\text { Treatment } \\
\text { soil }\end{array}$ & $\begin{array}{c}\text { Average } \\
\text { Germination } \\
\%\end{array}$ & $\begin{array}{l}\text { Average shoot } \\
\text { length }(\mathrm{cm})\end{array}$ & $\begin{array}{l}\text { Average root } \\
\text { length }(\mathrm{cm})\end{array}$ & $\begin{array}{c}\text { Total } \\
\text { Chlorophyll } \\
\text { content }\end{array}$ & MDA & Biomass \\
\hline Forest soil & $83 \%$ & 19.63 & 3.49 . & 575.94 & 1.82 & $0.117 \mathrm{~g}$ \\
\hline Mango soil & $78.75 \%$ & $21.54 *$ & 3.91 & 448.40 & 2.41 & $0.093 \mathrm{~g}^{*}$ \\
\hline Agriculture soil & $91.5 \%$ * & $21.77^{*}$ & 3.83 & 542.33 & 1.37 & $0.068 \mathrm{~g}^{*}$ \\
\hline Litchi soil & $66.25 \%$ & 15.56 & $2.70^{*}$ & $614.62 *$ & $3.88^{*}$ & $0.057 \mathrm{~g}$ \\
\hline
\end{tabular}

\section{Chemical analysis of soil}

The chemical properties of soil from different sites were given below-

\section{PH}

The $\mathrm{pH}$ of the soil in the agriculture was found to be highest (7.22) as compared to other soil i.e., mango soil (6.81), forest soil (5.04) and litchi (7.02)

\section{Moisture content}

The moisture content was highest in the agriculture soil $(92.8 \%)$ as compared to the remaining soil i.e., mango $(88.7 \%)$, forest soil $(82.1 \%)$ and litchi soil $(81.07 \%)$

\section{Discussion}

Study investigated in rice seeds grown in four different treated soils indicate that each soil carries different allelochemicals ranging from inhibitory to stimulatory effect on seed germination and growth. In this experiment soil supplemented with 5\% extract of Litchi litter is more inhibiting as compare to other treatments.

The shoot and root development is also greatly reduce when compared with seeds grown in other soil. This inhibitory effect in shoot and root development may be due to the presence of allelochemicals release by the decomposing debris of litchi in the soil. In an study it is observed that weeds under mature Litchi chinensis plant are very scanty. The inhibition on root growth is greater than hypocotyls/coleoptiles the reason may be due to the direct contact of roots with the allelopathic extracts which facilitate the first absorption of allelopathic substances by the root tissue than hypocotyls/coleoptiles. The maximum reduction in the biomass content was found in litchi which was followed by agriculture soil Whereas the maximum reduction in the shoot length and root length was found in litchi soil. While shoot, root and germination percentage is considerably reduce in litchi soil the chlorophyll content in the litchi soil was considerably higher inspite of the allelochemical stress as compared to other seed.

\section{Acknowledgements}

The authors thankfully acknowledge the Director of Doon (P.G) College Dehradun for their laboratory support.

\section{References}

1. Batlang U, Shushu D.D. "Allelopathic activity of Sunflower (Helianthus annuus L.) on growth and nodulation of Bambara groundnut (Vigna subterranean L.)" Journal of Agronomy. 6: (2007):541-547.

2. Noguchi H. "Allelopathic potential of two aquatic plants, duckweed (Lemna minor L.) and water lettuce (Pistia stratiotes L.), on terrestrial plant species". Aquat Bot. 103: (2012) : 30-36.

3. Nasir. H, Iqbal Z, Hiradate S, Fujii Y. "Allelopathic potential of Robinia Pseudo acacia L." J Chem Ecol. 31: (2005):2179-2192.

4. Teerarak, M, Laosinwattana, C Charoenying.P "Evaluation of allelopathic decomposition and cytogenetic activities of Jasminum officinale L. var. grandiflorum (L.) on bioassay plants". Bioresource Technol. 101: (2010):5677-5684.

5. Siddiqui, S.B, Lychee.S, Papademetriou, M.K, Dent FJ, Litchi production in the Asia-Pacific region. Bangkok, Thailand: FAO Regional Office for Asia and the Pacific; (2010): 8-40.

6. Rokiek, El, Kowthar.G, Rafat, R.E, Nadia. K and Salah, A "The Allelopathic Effect of Mango Leaves on the Growth and Propagative Capacity of Purple Nutsedge" Journal of American science (2010):6(9).

\section{Cite this article as:}

Menovikho Hoshi, Kamla Dhyani, Shweta Sahni, Chhaya Singh. Comparative allelopathic effects of mango, litchi, sal forest leaf litter on the germination and seedling growth of rice (Oryza sativa). Annals of Plant Sciences 5.7 (2016): 1392-1394.

DOI: http://dx.doi.org/10.21746/aps.2016.08.001 